\title{
Exploring the Experiences of Child Welfare-Focused Therapeutic Service Providers
}

\author{
Marianna L. Colvin \\ Heather M. Thompson
}

\begin{abstract}
The importance of mental and behavioral health for child welfare clients is well-documented; yet, little is known about the challenges therapeutic service providers (TSPS) experience working in child welfare practice. To explore this topic, five focus groups were conducted with 40 TSPs in a contracted mental and behavioral health agency and data were analyzed following an inductive thematic process. Eleven primary challenges were identified, including the difficulty of navigating numerous involved parties, an overwhelmed work environment, legal intersections common to child welfare cases, unrealistic agency expectations, and heighten case complexity when working with child welfare populations. Findings are organized across system, agency, and client levels and add to the understanding of TSP perspectives working with child welfare. Targeted interventions are discussed, such as efforts to promote realistic expectations and training strategies, as well as directions for future research to improve the intersection between child welfare and mental and behavioral health.
\end{abstract}

\section{Introduction}

The rates of trauma exposure ${ }^{1,2}$ and adverse childhood experiences ${ }^{3}$ are disproportionately high among children involved with the child welfare system. Youth placed in foster care settings are also at a heightened risk for developing posttraumatic stress symptoms. ${ }^{4,5}$ As a result, children in foster care are likewise more likely to experience mental and behavioral health needs, including concerns related to depression, anxiety, suicidality, risky sexual behavior, and delinquency. ${ }^{2,}{ }^{6-8}$ Continued mental and behavioral problems also increase the risk for higher restrictive foster care placement ${ }^{5,9}$ and contact with juvenile justice systems. ${ }^{10}$ Parents involved in the child welfare system themselves often have history with trauma and/or struggle with substance abuse, making child removal more likely ${ }^{11,12}$; the experience of child removal can consequently influence parental

Address correspondence to Marianna L. Colvin, School of Social Work, SO303, Florida Atlantic University, 777 Glades Rd, Boca Raton, FL 33431, USA. .

Heather M. Thompson, School of Social Work, SO303, Florida Atlantic University, Boca Raton, FL, USA.

Journal of Behavioral Health Services \& Research, 2019. 86-101. (c) 2019 National Council for Behavioral Health. DOI 10.1007/s11414-019-09654-8 
mental health. ${ }^{13}$ With over 1.2 million children receiving services in the USA following maltreatment referral in 2015 alone $^{14}$ and approximately 400,000 residing in foster care placement, ${ }^{15}$ the delivery and quality of behavioral and mental health care for children and families in this service setting are a priority and there has been a push in recent years to focus on the well-being of children within the foster care system. ${ }^{16}$

State child welfare agencies have increasingly turned to contracted providers to deliver a range of services and the wave of privatization has fueled diverse non-profit and for-profit participation in child welfare practice settings. ${ }^{17}$ Results from the National Survey of Child and Adolescent WellBeing $^{18}$ found that approximately $33 \%$ of foster care placement services and $59 \%$ of family preservation services are contracted out to private agencies. Therapeutic services for children and their family members are routinely contracted and there is an emphasized need for services to align with the focus on the well-being of children and families, ${ }^{19}$ yet, research aimed at understanding the experiences of contracted therapeutic service providers (TSPs) in their work with child welfare populations is limited.

Existing contributions in this area include an autoethnographic narrative of child welfare-focused therapists by Burns-Jager and colleagues in 2012 in which they highlight that families have complex situations in which no outcome may be seen as best and that they struggled as therapeutic providers to accept different forms of outcomes, such as the termination of a client's parental rights. ${ }^{20}$ Shea's 2015 online survey with therapeutic providers delivering attachment-based treatment to children in foster care found that they experience similar feelings of helplessness and hopelessness as the children they are serving, being without a significant sense of control within the system. ${ }^{21}$ Another study in Washington state involved interviews with child welfare caseworkers, but also engaged therapeutic providers through surveys. ${ }^{22}$ Both groups of professionals reported challenges working with clients involved in the child welfare system. Namely, caseworkers reported uncertainty about understanding the mental health needs of their clients, and therapists described difficulty addressing the complex client needs, exacerbated by multiple moves and varied family structures. Marcenko and colleagues in 2012 similarly identified that the multiple issues that child welfare-involved families face, including economic disadvantage, may impede their ability to participate in services with their providers. ${ }^{23}$ Others have also described challenges for child protection workers regarding client engagement and willingness to change. ${ }^{24}$ ${ }^{25}$ Given that research has indicated challenges for other child welfare professionals, it is important to examine challenges experienced by TSPs serving a child welfare population.

More broadly, studies examining the intersection between mental and behavioral health services and child welfare suggest concern for accessibility and provision of services. There is a well-documented gap between the number of children with mental health needs in the child welfare system and the receipt of services. ${ }^{26}$ Raghavan and colleagues in 2010 found that children in foster care overwhelmingly did not receive treatment services consistent with national standards, younger children even less so. ${ }^{27}$ Striking discrepancies identified by Glisson and Green in 2006 also indicated that only $23 \%$ of children in the child welfare and/or juvenile justice systems receive services, while approximately $67 \%$ have mental health needs that warrant treatment. ${ }^{28}$ They further propose that the significant turnover trends in child welfare case management can impede client access to mental health care.

Indeed, research on turnover and retention of child welfare professionals, such as child protective investigators and case managers, has indicated negative consequences for clients, ${ }^{29}$ yet, minimal research has focused on turnover rates and/or reasons for turnover among TSPs within the child welfare system. The study by Claiborne and colleagues in 2015 is a notable exception that examined specific organizational factors related to child welfare administrators and clinicians desiring to look for another job, identifying that manageable workloads, organizational support, and role clarity contributed to retention. ${ }^{30}$ These findings underscore the need for a more robust body of literature exploring the experiences of TSPs to identify and better understand the challenges they encounter and inform strategies to improve service delivery for children and families. 
Finally, in recent years, a shift to utilizing evidence-based interventions in child welfare practice has taken place and researchers have begun to consider associated challenges. ${ }^{31,32}$ A study conducted by Akin and colleagues asked facilitators of an evidence-based parenting intervention to describe the challenges associated with a child welfare-focused population. ${ }^{33}$ Facilitators described a gap in the intervention in addressing specific issues such as trauma, substance abuse and mental health, and likewise, significant challenges when trying to utilize the intervention with a diverse client population. Horwitz and colleagues ${ }^{34}$ identified specific means for possibly utilizing evidence-based interventions with a child welfare population, such as the use of interagency networks and ensuring agency philosophy and mission match those of evidence-based interventions. Given the push for the implementation of evidenced-based interventions in child welfare settings, ${ }^{31,32}$ related challenges may emerge for contracted TSPs in this setting.

In the current literature, perspectives from children and families ${ }^{35}$ and case managers ${ }^{36}$ regarding their experiences intersecting with mental and behavioral health treatment are represented; yet, research is limited that represents the lens of TSPs themselves. With the dominance of contracted therapeutic services for children and families, examination of TSP experiences is a fundamental component of achieving the safety, permanency, and well-being outcomes designated by the Adoptions and Safe Family Act. ${ }^{37}$ This exploratory study sought to better understand the experiences of TSPs directly, with specific emphasis on the challenges they encounter, when serving predominantly child welfare population.

\section{Methods}

\section{Research design}

As an exploratory study, a qualitative design utilizing focus groups was employed to gather depth in description from the population of TSPs. Qualitative methods offer the means to answer questions related to the experiences and perceptions of a study's population ${ }^{38}$ and were thus fitted to this study's purpose. Initiation of this study first emanated from expressed concern by administrators in a community-based care agency about gaps in the confidence of TSPs working with families involved in the child welfare system. A university-community collaboration was formed in response as a means for bridging the gap between education, practice, and research with specific attention for the translational value of research in community-practice settings. Such partnerships are noted to promote an understanding of barriers to implementing evidence-based practice and are often fundamental to the advancement of implementation science. ${ }^{39}$ Questions guiding the study were broad and intentionally constructed without a priori hypotheses, reflective of the exploratory nature of this inquiry. IRB approval was obtained through the university board prior to its initiation and the study was conducted as part of a grant-funded project through a state institute. No conflicts of interest were identified.

\section{Sample}

The sample for this study was drawn from a private, community-based agency located in the Southeastern United States. Five focus groups were conducted with TSPs $(n=40)$. Participating TSPs were primarily full-time employees who provide a range of mental and behavioral health services to children and families, including trauma therapy, individual, group, and family therapy. TSPs do not receive formal training at the agency on a particular therapeutic modality and are able to choose the interventions that they deem clinically appropriate. As reported by the agency, the majority of families served are involved in the child welfare system. A range of professional degrees were represented in the sample, including Masters or doctoral degrees in social work, psychology, mental health counseling, and marriage and family therapy, as reported during the focus groups. Tenure with the agency among TSPs in the sample ranged from being recently hired to several years. To ensure confidentiality of the participants and to reduce social desirability, no demographic information was collected on the participants in this study. 
The client population served by the agency ranges across the lifespan, including young children ages 5 and under (20\%), children ages 6-17 (54\%), and adults (26\%). The client population is also racially diverse. Forty-two percent of clients classify themselves as Black, 38\% White, and the remaining $20 \%$ were multiracial, biracial, Asian, choose not to answer, or other. Sixteen percent identify as Hispanic. As reported by agency administrators, the majority of families served (78\%) qualify for Medicaid and a significant portion are involved in the child welfare system.

\section{Data collection}

Researchers introduced this study to TSPs during a regularly scheduled staff meeting. The purpose of the study was explained and focus groups were scheduled to align with regular weekly meetings in order to decrease the burden of participation. No staff meetings took place during the focus groups to prevent perceived coercion of participation by administrators. Five focus groups were conducted across a 2-month time span in 2016. Each focus group was facilitated by one of the authors of this paper and a graduate research assistant assisted with making audio recordings and collecting informed consent forms. Prior to beginning the focus groups, informed consent was explained orally, including the purpose of the study, confidentiality, and the voluntary nature of participation. It was reiterated that no record was being kept of who attended the focus groups, specifically that administrators would not be informed of who did or did not participate, and that participants were free to discontinue participation in the study at any point. Written informed consent was also obtained from all individual participants included in the study. No incentives were provided for participation.

Each focus group was facilitated using a semi-structured interview protocol. Questions focused on how prepared TSPs felt in their current role and their experiences as TSPs, specifically working with child welfare clients with emphasis on challenges encountered, as well as areas in which they wish they had additional knowledge or skill development. Each focus group had between 6 and 12 participants and lasted approximately $60 \mathrm{~min}$. All were audio recorded and transcribed verbatim. Transcripts were imported into Atlas ti for data management and coding. ${ }^{40}$

\section{Data analysis}

This study sought to identify challenges experienced by TSPs in their work with child welfare clients and was exploratory given the limited qualitative research conducted from the perspective of TSPs themselves. Data were examined using thematic analysis procedures ${ }^{41}$ in an inductive process beginning with open coding, followed by axial or focused coding stages to identify challenges. With the intent to be driven by the data in line with an inductive process, ${ }^{42}$ coding was completed with no a priori codes. Instead, transcripts were coded for challenging phenomena or experiences evident in the data and codes were generated to label moments and expressions prior to interpretation. ${ }^{41}$ This initial coding procedure was undertaken by both authors of the study independently. Codes were then considered for patterns and organized into themes. Subthemes were maintained within dominant themes when warranted by code frequency and conceptual distinction and themes themselves were organized into a framework distinguishing the levels (i.e., system, agency, or client) in which challenges were evident.

Extensive rigor was sought across the analysis process. Once the coding scheme was developed, it was applied by both authors to a full transcript (20\% of the data) to calculate intercoder reliability. The initial code-by-code match was $94 \%$ and the few discrepancies identified were discussed to reach full consensus. Throughout, active reflexivity and memoing was practiced by the authors with recognition of their role in the research process. ${ }^{43}$ The authors have diverse child welfare practice experiences, each in different state systems and in different capacities, with roles spanning protective services, family preservation, and administration for the first author and foster care and therapeutic services for the second. The high intercoder consistency between authors despite diverse practice experiences further supports the reliability of findings. Extensive quotes from the data are also provided to describe and support the derived themes. 


\section{Results}

In total, 11 primary challenges were evident across three identified levels: (1) system level, (2) agency level, and (3) client level. The identification of levels was, itself, a standalone finding and was not preconceived prior to analysis. Figure 1 visually depicts each theme as fitted to the three levels, and also communicates the way in which some challenges at the system level were perceived to manifest as differential challenges at the agency and client levels.

\section{System level}

At the system level, TSPs described experiencing challenges related to four primary contextual characteristics of the child welfare system: (1) numerous involved parties, (2) an overwhelmed work environment, (3) the legal intersection, and (4) system instability.

Numerous involved parties The challenge of encountering numerous involved parties (i.e., court and legal professionals, child protective service professionals, service providers, foster parents, biological parents and relatives, and so forth) was the most prevalent theme across focus groups. This contextual characteristic of child welfare practice appeared to manifest as a challenge for TSPs in a variety of ways. The most widely expressed was communication.

TSPs faced barriers communicating in ways as fundamental as knowing 'who is who' among the variety of professionals involved with child welfare clients: "We don't know what is going on, we

\section{Figure 1}

Challenges experienced by therapeutic service providers at the system, agency, and client levels

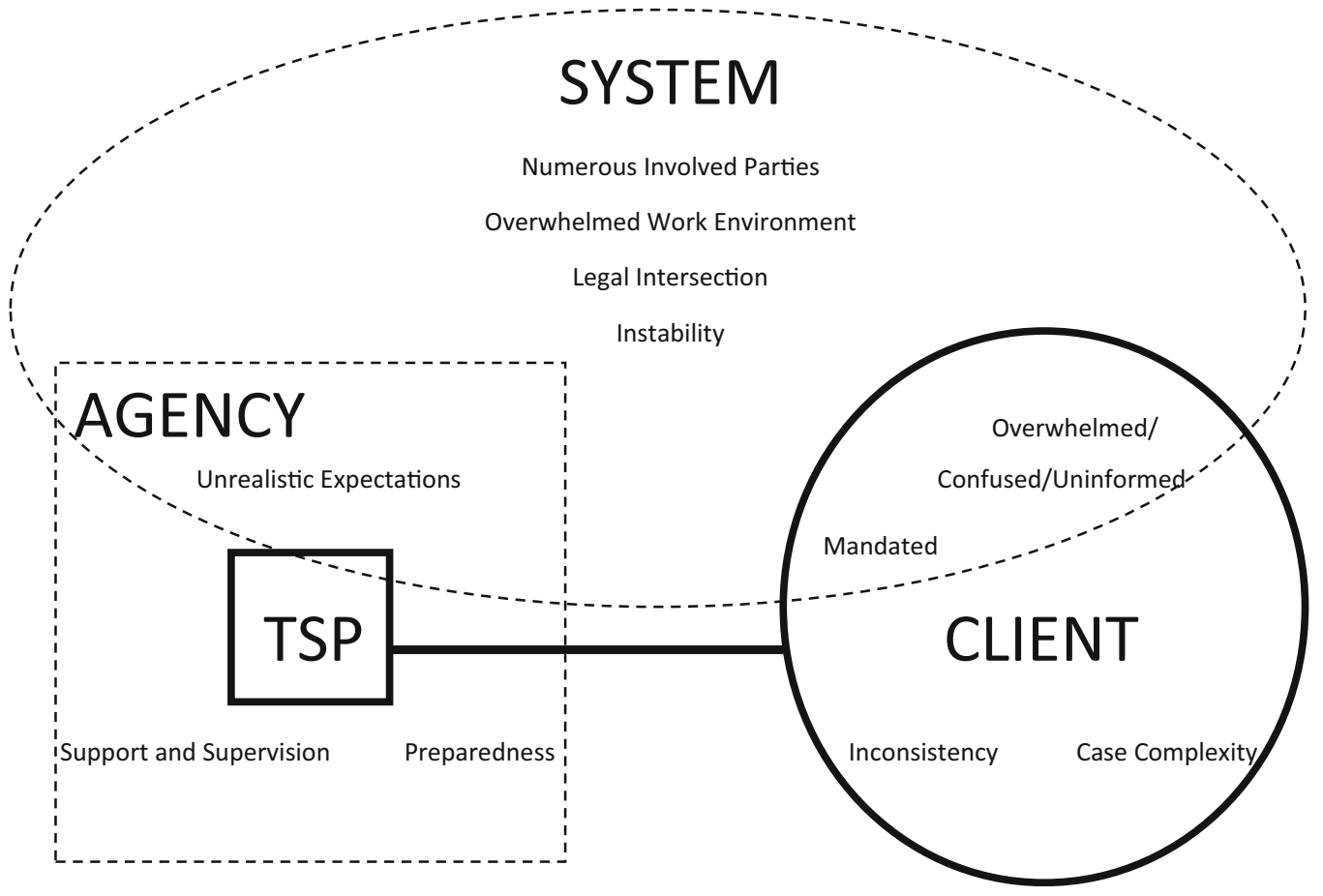


don't know who to talk to." By extension, connecting with and receiving a response from other professionals was described as difficult. For example, when asked what would be helpful in their role, one TSP stated bluntly, a "dependency case manager that answers phone calls and emails." Another reiterated, "Because that is the hard part, communicating." TSPs also consistently emphasized the importance of interprofessional communication for case trajectory. As an example, one TSP reflected, "Sometimes even brief communications can go a long way...knowledge of that child's specific triggers...the sooner those things are known and shared between the players of the team...that can, again, avoid a lot of obstacles."

Role confusion was also described within the challenge of navigating numerous involved parties. One TSP explained, "We don't know what our roles are...should we respond to [biological] mom? Should we respond to the foster mom ... there are a lot of people involved." TSPs also described a lack of information sharing and access among professionals, particularly with expressions of frustration. One TSP stated, "They [dependency case managers] don't even return your calls and the foster mom [will] say something and then you are like 'What happened?" Others communicated that not sharing information can often derive from not being able to identify relevant case contacts. One TSP reflected, "I've got one kid, he's been there for three weeks and I have no idea who the investigator is, who he has been assigned to." Information sharing was similarly expressed as a concern in long-term foster care cases, in the form of not understanding case goals. When information is not shared, TSPs specifically expressed being at a disadvantage therapeutically:

[Dependency case managers; DCMs] need to also provide the case plan...so that we can all kind of be on the same page. eEven if it is impossible to get in touch with the DCM, at least we know what they know and at least we have the information that they have... ilf you're not really getting in touch with the DCM and the DCM isn't getting in touch with you then all you really have is, to go on, the client's perspective. So, you're already going to have some kind, you know, bias there.

Further, when communication does take place, the quality of communication among professionals was described to be deficient and often last minute:

They contact you and they say 'Are [you] using CBT [therapeutic modality] with anger management?' And, you know, it is like they just kind of check off their boxes so that they can report to the court...but then there is no further conversation usually after that.

Another reiterated, "It [communication] becomes important when they [dependency case managers] need their summary for court and then they call you, like, that day."

Within this theme, an element of relationship quality with other professionals also emerged. For example, one TSP described a situation of feeling blamed for a client's inconsistency and another lamented: "I don't think they [the court] ... see the therapist as an important part of this whole process." Another summarized, "You are part of the team when they [dependency case managers] want you to be part of the team."

Overwhelmed work environment In the expressions of difficult communication, TSPs heavily acknowledged that their various professional counterparts are overwhelmed. It was evident that it was not strictly the number of involved parties that posed a challenge, but that the work environment of other professionals in the child welfare system was a barrier. One stated, "The communication between dependency case managers and us is minimal. You have to chase them down. I'm talking, like, email after email, phone call after phone call. It's just, they're overworked and they're so understaffed over there." Another reflected, "There are many times when they [dependency case managers] just don't, they don't know what is going on and we have to remember that they've got an unbelievable number of children that they are dealing with." It was specifically apparent that turnover in child protective services contributed to this challenge. TSPs noted across focus groups that case managers change often and recognized environmental pressures 
as a challenge: "It is the system putting so much pressure on the workers and making them do so much, when it is already a draining field."

Legal intersection The presence of a legal intersection in child welfare cases was consistently highlighted as a challenge by TSPs. As a prominent example, subpoenas were unanimously discussed across focus groups in a negative light. One TSP stated plainly, "My biggest fear is being subpoenaed." It was evident that uncertainty around what can and what cannot be shared in court settings underlined the majority of concern and TSPs specifically expressed confusion and fear related to "not overstepping confidentiality boundaries."

TSPs also struggled with how appearing in court can potentially threaten the therapeutic relationship with clients. One TSP recalled a time when "the dependency case manager blasted the [TSP's] notes in court." The TSP explained that "[the case manager was] basically telling the kid, 'You told me you worked on Monday and it said you didn't work on Monday in the progress note." The TSP went on to describe, "so that is now tainting the relationship with the therapist because the client's coming back like 'Confidential much?' [read with sarcasm]." Additional challenges within this theme related to TSPs struggling to align client goals with court ordered treatment, as well as instances of it being difficult, but necessary, to "stand up to the court system" with a therapeutic recommendation.

Instability A final theme at the system level emphasized how therapeutic progress is often thwarted by the instability common to child welfare cases:

You know, it is like they [children] make a little bit of progress and they go back, you know, they backslide a little bit because they are going back to the same environment where the trauma happens to begin with. So it is a roller coaster.

Disruption of sibling placements, "Their siblings have been removed, you know, not keeping them together" and changes in caregivers were additional examples of instability highlighted by TSPs as a challenge in their therapeutic work. For example, one TSP reflected on a case, "They [the children] moved to another foster home...without having, like, a consistent caregiver. That's extremely difficult [therapeutically]."

System instability was additionally described as a disruptive factor in the TSP/client relationship:

You are building rapport with them [the kids] and trust and, you know, going through what they are going [through] and then you get a call when they [case managers] are like, 'Oh, you know, we are going to change the therapist.'...

It's hard for the kids to just be removed from one person [TSP] to another person.

This instability was specifically perceived by TSPs to have long-term consequences. One TSP described, "Some of them [children] were very reluctant to go back in the therapy because they would go from one therapist to another therapist to another therapist."

\section{Agency level}

In addition to the data illustrating system level challenges, TSPs expressed experiencing three primary challenges at the agency level: (1) unrealistic expectations, (2) support and supervision, and (3) preparedness.

Unrealistic expectations The discussion across focus groups revolved heavily around unrealistic agency expectations. Two primary subthemes were evident within this challenge: (1) push for quantity over quality and (2) personal and professional balance. 
Expressions in the subtheme 'push for quantity over quality' underscored the perception among TSPs that a push for quantity in agency expectations interferes with therapeutic quality. For example, TSPs described that an emphasis on billable hours resulted in pressure to add clients to their caseload despite lacking competence:

The push for productivity is so great here that you have some [TSPs]...they see clients on the waitlist and they need to get their caseload [up] and it's survival of the fittest... They'll take a client who is five years old even though they...have no training whatsoever in that client [population].

Another conveyed that the pressure for making required productivity hours results in providing services in ways they would otherwise avoid:

We are so desperate to make hours, we go like 'Okay, I will see you at 8pm, okay I will see you at seven. When can you see me? Saturday? Fine. Sunday, oh okay.' I mean we are so desperate, I mean it's...horrible. Like, you know everybody is like 'Set boundaries, set boundaries.' There is no boundary.

TSPs commonly expressed feeling discouraged and an element of guilt due to being spread so thin given the expectations, including not being able to individualize sessions and practice therapy in the way they would like. One lamented:

You are doing therapy with these people and, like, you want it to be the best that you can with them and plan for the session, individualize everybody, but you really can't. You have to kind of be like, 'okay, next, next, next.' And it is just, it is like a huge lack of - I mean for me that is a lack of quality. That really, really bothers me...

TSPs similarly expressed that productivity expectations do not account for the often high needs of a child welfare client population, and that trying to provide quality therapeutic services while still meeting required productivity hours is a challenge:

If I have a client...that is homeless...my intention is to want to help that client to get resources...But then your supervisor will flat out tell you, 'That's not your job description'... So if I spend time to do that for a client, then I'm spending time taking away from other productivity...then at the end of the month, I'm going to get screwed for that.

Another reiterated the influence of multiple client needs on therapeutic progress stating, "I can't really do my best therapeutic work if you [the client] don't have child care, if you don't have diapers or your baby doesn't have formula", yet TSPs expressed feeling like they have to say a 'Sorry, I cannot help you. I cannot bill for that." Similarly, TSPs expressed the importance of accounting for high therapeutic client needs when setting quantity or productivity standards. One TSP suggested:

If [a TSP] has four, five cases that are really high profile, like really draining, cut her some slack. Maybe she doesn't have to do 25 that time. You know. I mean, because they need to be focusing on the quality of work [the TSP] is providing to those clients.

The second sub theme under unrealistic expectations was labeled 'personal and professional balance' and described a challenge in managing required workloads in the form of meeting requirements, negotiating logistics, and balancing professional and personal priorities. As summarized by one TSP, "There's just not enough hours in a day." Even TSPs who expressed understanding the importance of self-care voiced exasperation with the feasibility of keeping up with job demands: "I don't have a family. I don't have kids. I consider myself very good at self-care...I'm a trained yoga instructor...I coach people in self-care and it has, since starting this job, self-care has fallen to the wayside."

Similarly, a feeling of personal sacrifice for the job was evident across focus groups and TSPs poignantly described not being able to balance personal and professional demands:

So, either my home is in order and everything is good and happy at home and work is suffering. Or, I'm bringing home stuff... working a lot and my toddler is running around screaming and crying because I'm not giving him any attention ...

Another reflected:

Before I was working here last Fall, you know, they [my children] would have soccer and have performances and stuff like that...now they cannot do that because I am not there... 'Mom gets off too late'... So that [extracurricular 
activities] is something that has to go because now I'm working from 8am till 7, 8, 9pm, you know, and sometimes on the weekends.

TSPs also communicated that the pressures of their work influenced their personal life choices. One exclaimed, "Like, I cannot even think about having a baby. How am I going to do it? I mean, that is unfair, that is really unfair." Another reiterated, "I don't even have kids and I still feel the same way. How am I supposed to meet someone? It's like my boyfriend is the laptop."

Overall, it was evident that TSPs struggled to manage work expectations and communicated that it affected them in personal ways. One TSP expressed this concern as, "We're spread so thin with all the responsibilities that we have. It's so easy to get burned out."

Supervision and support The desire among TSPs for quality supervision was described extensively and, when missing, was highlighted as a particular challenge. The defining characteristics of supervision expressed by TSPs as important included supervisors being accessible, supportive, and competent. TSPs specifically described that the chaotic and nontraditional hours of their work with a child welfare client population meant that they needed access to supervision at all hours, and the element of support from a direct supervisor was highlighted as critical. One TSP summarized, "A supervisor that backs you up where you don't have to defend yourself all the time and like really empowers you...I think it helps relieve a lot of pressure." Another denoted that supervision presented significant challenges: "No one is looking out for us, no one is saying 'You know what, my therapist is doing the best she can and if there needs to be an area of improvement we are going to back her up." Another explained, "Just like we [TSPs] show parents...as therapists, we learn as we go too....and consistent reflective supervision helps."

In addition to supervision being accessible and supportive, the quality of supervision in the form of competence and experience was described as an additional challenge within this theme. TSPs denoted the need for a "truly experienced supervisor who knows exactly what the bumps [are]." It was consistently reiterated that an experienced supervisor matters:

Because then they know what you're going through. They feel your pain a little bit. They get it, they've done it.

They've had the caseload, they've had the paperwork. So, now, as a supervisor they can really be there to help you.

Overall, TSPs emphasized the importance of supervision in relation to their success as therapists and their interaction with clients. One reflected, "I've been in this field for ten years. I've seen a lot of therapists fail due to lack of skilled supervisors."

Preparedness Another prominent theme that emerged across the focus groups was TSPs feeling unprepared to work with the child welfare population. One TSP explicitly stated, "I got little preparation." Instead, TSPs consistently reflected that previous education programs and agency training were not adequate for the responsibilities and tasks the job entailed. A common description was TSPs finding themselves in a "learn as you go" environment:

They [the agency] were like 'Here......do your job' and I said, 'Okay, I don't even know how to fill out, like, the [forms].' I have never done that in my life ...so it was like learning as you go, [pause] as you mess up.

Some TSPs reported that being unprepared was a particularly taxing experience due to the desire to want to provide the best services possible, yet feeling inadequate. One stated, "A lot of times you come into this field and you have never dealt with anything like that. You have never dealt with people threatening to harm themselves or whatever, and you really don't know what to do." As a result, TSPs reported resorting to various methods to make up for the perceived lack of preparation. One reflected, "I'm not the best person to help them because I haven't been trained...so I am looking things up to figure out [what to do].” 
TSPs also communicated the desire to enhance their competence and skills to provide better quality services, but felt unsupported at the agency level:

If I've used my ten hours for the year of training [and] there's a training that I want to go to and I, if I really want to go, I have to take vacation or a sick time or personal time to do that training. Like I'm getting training to benefit the agency...I should not use my vacation time to come to a training to help improve my knowledge of the clients that you guys [the agency] are giving.

\section{Client level}

Four challenges were evident at the client level. Two of the four-clients are overwhelmed/ confused/uninformed and mandated clients - were placed at the client level in analysis given that each was experienced by TSPs in their engagement with clients, but these themes are notably also related to identified system level challenges.

Clients are overwhelmed, confused, and uninformed TSPs specifically described their child welfare clients as overwhelmed, confused, and uninformed, all of which pose challenges for TSPs in their therapeutic work. For example, one TSP stated:

It is totally different thing, private practice, they [clients] are seeking your services versus child welfare...you know, [child protective services] is referring them, but they [child welfare clients] don't really know who you are and why you are there or what even therapy is.

Other TSPs expressed that parents routinely lack an understanding of the processes involved. One explained, "The parents or the guardians... are like, "Why am I having 50 different people calling me?'” Another described, "I asked my client, 'Do we have a case plan? [and they responded] 'Case plan? What's that?" Another reiterated:

The parents are like, 'Okay, yeah, come on, come on, come on, because I'm trying to get my case plan done' but they

are really confused, too, because they don't know what's going on...it becomes overwhelming for them.

Within this challenge, TSPs described having to take on educational and liaison roles between parents and child protective services. One described the importance of needing to know "how to explain [the system] to people," such as what visitation and reunification processes look like. Another echoed: "And even like the court structure with the judicial reviews, how all that happens...we can help the client to understand the process and the foster parents because...we get a lot of questions about that." Another summarized blatantly, "You got clients that don't have a clue."

Notably, although TSPs encountered this challenge during direct interactions with clients, it was perceived to be connected to the challenge of having numerous involved parties and the legal intersection at the system level, suggesting that challenges manifest differently and impact TSPs in multifaceted ways. Overall, TSPs conveyed that experiences with the child welfare system produced clients who were routinely overwhelmed and confused, resulting in challenges achieving therapeutic work and the emergent need to also serve as an educator and liaison to buffer client experiences.

Mandated clients Across focus groups, TSPs highlighted the challenge of engaging mandated clients in therapeutic services, which is a routine characteristic of child welfare cases. One summarized this theme succinctly, "They [mandated clients] don't want the services. So just engaging them in the process takes more time and it's much more difficult." Again, although working with mandated clients was designated as a client level challenge given that it occurs when 
encountering the client directly, it is an additional challenge that is linked to the presence of a legal intersection at the system level.

Inconsistency TSPs further described that the prevalence of inconsistency on the part of the child welfare client population posed a challenge, in the form of inconsistent session attendance and reachability. One TSP stated simply that "your week is not going to go the way that you wanted to, ever." Another exclaimed, "I had six cancellations last month and yeah, so it was [laughs with exasperation]..." An element of stress was evident within this challenge in relation to managing productivity expectations, as described in the following quote: "When dealing with clients that, you know, are missing, you can't get with them and whatnot, it kind of hurts you. Their inconsistency hurts you... [It] can be very stressful." It was evident that the challenge of working with clients who may be inconsistently available for services seems to be exacerbated by the agency level challenge of unrealistic expectations related to productivity.

Case complexity Finally, the last challenge at the client level speaks to the complexity of cases TSPs encounter within a child welfare context. Specific elements of complexity described by TSPs include the multifaceted needs of child welfare clients, the presence of trauma, the cyclical nature of child maltreatment, competing priorities between parents and children, and the dynamics of treating the family as a whole. This complexity is difficult for TSPs in a variety of ways. One explained, "The cases I got are heavy trauma cases and they're like really draining." Other TSPs described the intensity of multifaceted client needs and the crisis environment: "Especially working in the child welfare population...there are so many different needs that our families have, it's not like just therapy. It's a lot of putting out fires, too."

TSPs consistently reiterated that their child welfare cases required heightened competence and skill as therapists: "We've got some real hardcore families and some real deep end issues that are going on."

In summary, the organization of the 11 themes identified in this study is reflected in Figure 1. Figure 1 also illustrates the ways in which themes were perceived to manifest across system, agency, and client levels, as described in the presentation of results. Specifically, some challenges at the system level were perceived to contribute to differential challenges at the agency and client levels and to likewise influence TSPs in multiple ways. As an example, unrealistic expectations were primarily expressed in relation to agency level structures, procedures, and policies, but system level challenges appeared to contribute to the complexity and magnitude of agency expectations. Intersecting and connecting lines in Figure 1 further reflect the presence of multiplex relationships among clients, the agency, and the larger child welfare system. Recognition of such intersection reinforces the cross-over effects described by TSPs. For example, navigating numerous involved parties creates hurtles in the form of interprofessional communication at the system level and differentially poses a challenge for TSPs by contributing to the creation of an overwhelmed and confused client population. Note that the use of solid lines highlights the client-worker relationship that is central to therapeutic intervention. The connection between these two individuals (i.e., the client and the TSP) is likewise distinguished in the context of larger entities represented by dotted lines (i.e., the agency and the system). What follows is a discussion of themes and implications for behavioral health and child welfare services.

\section{Implications for Behavioral Health}

The purpose of this study was to identify the perceived challenges experienced by contracted TSPs in their work with a child welfare client population. Eleven primary challenges were evident 
in the data and were found to exist across three distinguishable, yet interrelated levels: system, agency, and client. Challenges at the intersection of child welfare and mental and behavioral health have been noted in other studies, ${ }^{15}, 17,18,20$ but rarely using qualitative focus groups with TSPs themselves to give voice to their experiences. Therefore, this study deepens knowledge of challenges from the perspective of this key stakeholder group and findings suggest numerous implications.

Given that challenges were evident at multiple levels, data in this study point to implications both external and internal to mental and behavioral health agencies serving child welfare clients. The challenge of navigating numerous involved parties, particularly the importance of role clarity and clear communication, is consistent with other studies that highlight the difficulty of collaboration across organizations and professionals in child welfare contexts. Case managers in the child welfare system, in particular, have reported similar struggles ${ }^{44}$ and research has suggested strategies to improve crossorganizational collaboration in child welfare service settings. ${ }^{22,}{ }^{45}$ However, data in this study demonstrate that barriers persist in practice and highlight some of the specific intricacies in which TSPs experience interprofessional and interorganizational interactions. For example, descriptions by TSPs suggest a feeling of being undervalued in interprofessional relationships. Examples include when information is either not shared with TSPs or shared as an afterthought, or when therapeutic recommendations are dismissed. Recognition by other child welfare professionals of the extent to which contracted providers rely on them as sources of information-information often paramount to therapeutic work - is important role recognition within the parameters of confidentiality. Such recognition may require enhancing empathy across professions and perhaps across organizations themselves. ${ }^{46}$ Given that feeling undervalued is also a noted experience for child welfare case managers in other studies, ${ }^{47-49}$ this finding may be interpreted as support that the design of current child welfare systems falters in valuing frontline practitioners, in general, and raises considerations for what appears to be a multi-organizational experience.

Interorganizational and interprofessional training is one avenue that may enhance communication and collaborative relationship quality among the numerous entities involved with child welfare families. ${ }^{50,51}$ Data from this study suggest that trainings not be isolated within single agencies or single provider sectors, but include an interprofessional orientation to promote multiple perspectives. In such endeavors, considerations for implementing training in ways that promote attendance despite high demand work environments $^{52}$ and continuous education strategies may be critical to counter high turnover. Additionally, the use of shared databases within the parameters of confidentiality that allow access by multiple providers may promote the sharing of information and reduce barriers to the communication of critical components of child welfare cases. Chuang and Wells in 2010 suggested the importance of improved collaborative strategies and found that for youth in long-term foster care who were dually involved in the juvenile justice system, interagency collaboration and sharing of information was correlated with an increased receipt of behavioral health services. ${ }^{53}$

Such initiatives may likewise serve to reduce challenges evident per the legal intersection common to child welfare cases and specifically highlighted by TSPs as a challenge in their work with families. By educating court personnel about the work of TSPs and raising awareness of how legal involvement can influence clients therapeutically, the experience of professionals and clients may improve. This interprofessional exchange may extend, too, to include building recognition for how to actively consider the effects of instability in how case decisions are made and implemented. Findings herein specifically highlight that consideration is needed for how the instability common to child welfare cases may influence therapeutic progress. While the goal of reducing disruptions in placement is widely-recognized ${ }^{54,55}$ and studies have suggested negative effects of child protective service worker instability on clients, ${ }^{29}$ the effects of instability of contracted providers themselves are comparatively limited. Findings from this study suggest the need to consider the effects of therapeutic provider consistency and potential strategies for promoting that consistency, as well as the design of strategies for increased involvement by TSPs in the planning and implementation of changes experienced by clients. 
At the agency level, attention to the experiences of TSPs suggests targeted intervention to promote realistic expectations, competent and dependable support mechanisms, and both initial preparedness and ongoing professional development. The emotions described by TSPs when expressing challenges at the agency level (e.g., frustration, stress, guilt, sacrifice, and discouragement) collectively raise alarms about retention of TSPs in the field. Again, while literature specific to turnover and burnout among child welfare case managers is extensive, research targeted to contracted providers and related effects of turnover among this stakeholder group is limited and is needed to better understand if and how the challenges TSPs encounter are related to their retention and/or client outcomes. Claiborne and colleague's 2015 exploration of retention factors specific to clinical professionals - both administrators and clinicians - indicated that organizational support, manageable workloads, and role clarity may be critical components of stabilizing the TSP workforce. ${ }^{30}$ These were each evident challenges experienced by TSPs in the current study and highlight an important opportunity to intervene. Strategies such as targeted caseload reduction, accounting for case complexity in case assignments, and streamlining documentation were communicated by TSPs themselves as potentially helpful. Furthermore, TSPs reported the need for self-care and boundaries, which can be supported on an administrative level through work hour limitations, supporting time off, and agency recognition for the unpredictability of the client population. The prevalence of and impact of compassion fatigue and need for self-care in the child welfare workforce is well-documented ${ }^{56,57}$ and results of this study suggest dedicated attention to similar experiences and response strategies for contracted TSPs, as well.

Investing in supervision, too, may simultaneously help to assuage a variety of identified challenges. Supervisors have the potential to monitor and enhance case competence, model and emphasize a focus on quality, promote and facilitate self-care, and reduce worker stress. Kim and Mor Barak in 2015 found that organizational support and exchanges between workers and administrators mediated the connection between role stress and turnover. ${ }^{58}$ Therefore, the more workers felt they interacted with leaders and received support from the organization, the more likely they were to remain in their positions, despite the stress of the job. Interestingly, supervisors within the child welfare field also report the need for quality supervision for themselves. McCrae and colleagues in 2015 found that child welfare supervisors who reported receiving supervision were less stressed and were also able to provide more supervision to their workers - an apparent reflection of the need for strong organizational leadership. ${ }^{59}$

Finally, findings of this study also suggest the need for training and ongoing professional development within designated work hours. In addition to interprofessional and interorganizational training, results suggest that training should specifically emphasize engagement with mandated clients and working with multi-need families. A particularly pertinent finding is that data in this study illuminate a need for TSPs to be prepared to act in a liaison role between clients and the child welfare and court systems. The challenge of overwhelmed, confused, and uninformed clients is a finding that is consistent with other studies where parents have reported that while services in the child welfare system may have an aim of improving family functioning, parents often experience many barriers and do not feel empowered through their service plan. ${ }^{60}$ It points to implications for the larger system, although given the role TSPs described, supervision at the agency level and targeted training for TSPs may offer tangible strategies for improving how clients understand and are supported in their encounters with the child welfare system.

\section{Limitations and directions for future research}

Although the current study illuminates the challenges TSPs encounter serving child welfare population, numerous limitations should be noted. First, while 40 TSPs participated in the study, the sample was drawn from a single mental and behavioral health agency in a metropolitan county in the Southeastern US. To counter this limitation, extensive quotes were provided to describe the 
construction of themes and enhance the ability to interpret their transferability. Further, focus group methodology compared to individual interviews may have introduced elements that altered how TSPs communicated their experiences, particularly challenges. Consensus was evident during data collection, noted frequently through nonverbal and verbal agreement, yet it is not known how responses would have differed if expressed through confidential means. Also, while intercoder reliability procedures and the authors' differential experiences from different child welfare state and county systems help to reduce subjectivity during data analysis, the influence of the researchers is not completely erased.

Despite these limitations, the results of this study suggest numerous directions for future research. A prominent example is the need for follow-up to better understand the emotions or feelings (e.g., guilt, stress, discouragement) evident in connection with described challenges. Emotions, explicitly, were not coded in the current analysis, but the communication of emotions was so intricately intertwined with the communication of challenges that their presence suggests that TSPs are affected in deep and personal ways and further heightens the need for inquiries that examine the relationship between these experiences and retention among TSPs in the field. Furthermore, future studies could include the instability within the child welfare system and its impact on the therapeutic process. Specific strategies could also be evaluated for reducing workload of TSPs and its relationship to the quality of services for clients.

Additionally, this study, along with previous research, point to a need to understand the collaboration of multiple professionals in the child welfare system. Future studies could involve multiple stakeholders, such as case managers, TSPs, other professionals, and clients to more fully understand the experiences from multiple perspectives. Study designs that measure the extent to which challenges are experienced and the relationship with client outcomes are also needed, as well as evaluation designs that track the effectiveness of response strategies indicated by the current findings. Additionally, this study highlighted the need for trainings to address many of the challenges identified. Future studies could evaluate the effectiveness of trainings addressing these challenges. As is, this study offers insight into the experiences of TSPs and highlights specific areas to target to reduce the challenges they encounter in their practice with vulnerable children and families.

\section{Acknowledgements}

This study was supported by a grant from the Florida Institute for Child Welfare.

Funding M.L. Colvin and H. M. Thompson received funding through the Florida Institute for Child Welfare for this project. No conflict of interest has been identified.

\section{Compliance with Ethical Standards}

Conflict of Interest The authors declare that they have no conflicts of interest.

Ethical Approval All procedures performed in studies involving human participants were in accordance with the ethical standards of the institutional and/or national research committee and with the 1964 Helsinki declaration and its later amendments or comparable ethical standards. This article does not contain any studies with animals performed by any of the authors.

Informed Consent Informed consent was obtained from all individual participants included in the study. 


\section{References}

1. Stein BD, Zima BT, Elliott MN, et al. Violence exposure among school-age children in foster care: Relationship to distress symptoms. Journal of the American Academy of Child and Adolescent Psychiatry. 2001; 40: 588-594.

2. Greeson J, Briggs EC, Kisiel CL, et al. Complex trauma and mental health in children and adolescents placed in foster care: Findings from the National Child Traumatic Stress Network. Child Welfare. 2011; 90: 91-108.

3. Finkelhor D, Turner H, Ormrod R, et al. Violence, abuse, and crime exposure in a national sample of children and youth. Pediatrics. 2009; 124: 1411-1423.

4. Kolko DJ, Hurlburt MS, Zhang J, et al. Postraumatic stress symptoms in children and adolescents referred for child welfare investigation. Child Maltreatment. 2010; 15: 48-63.

5. Kisiel CL, Fehrenbach T, Torgersen E, et al. Constellations of interpersonal trauma and symptoms in child welfare: Implications for a developmental trauma framework. Journal of Family Violence. 2014; 29: 1-14.

6. Grogan-Kaylor A, Ruffolo MC, Ortega RM, et al. Behaviors of youth involved in the child welfare system. Child Abuse \& Neglect. 2008; 32: 35-49. doi:https://doi.org/10.1016/j.chiabu.2007.09.004

7. Leathers SJ. Foster children's behavioral disturbance and detachment from caregivers and community institutions. Children and Youth Services Review. 2002; 24: 239-268. doi: https://doi.org/10.1016/s0190-7409(02)00175-5

8. Leslie LK, James S, Monn A, et al. Health-risk behaviors in young adolescents in the child welfare system. Journal of Adolescent Health. 2010; 47: 26-34. doi: https://doi.org/10.1016/j.jadohealth.2009.12.032

9. James S. Why do foster care placements disrupt? An investigation of reasons for placement change in foster care. Social Service Review. 2004; 78: 601-627.

10. Halemba G, Siegel G. Doorways to delinquency: Multi-system involvement of delinquent youth in King County. Pittsburgh, PA: National Center for Juvenile Justice; 2011.

11. Lesperance T, Moore KA, Barrett B, et al. Relationship between trauma and risky behavior in substance-abusing parents involved in a family dependency treatment court. Journal of Aggression, Maltreatment \& Trauma. 2011; 2: 163-174. doi: https://doi.org/10.1080/ 10926771.2011 .546752

12. Taylor OD. Children of substance-abusing or substance-dependent parents. Journal of Human Behavior in the Social Environment. 2011; 21: 727-743. doi: https://doi.org/10.1080/10911359.2011.6156831

13. McWey LM, Henderson T, Tice SN. Mental health issues and the foster care system: An examination of the impact of the Adoption and Safe Families Act. Journal of Marital and Family Therapy. 2006; 32: 195-214.

14. U.S. Department of Health and Human Services. Child Maltreatment 2015. 2017. Available online at https://www.acf.hhs.gov/cb/ resource/child-maltreatment-2015. Accessed 12 March 2019

15. Child Trends Databank. Foster care. 2015. Available online at https://www.childtrends.org/?indicators=foster-care

16. Mason S. Child well-being as a federal priority in child welfare. Families in Society: The Journal of Contemporary Social Services. 2012; 93: 155-156.

17. U.S. Department of Health and Human Services. Evolving roles of public and private agencies in privatized child welfare systems. 2008. Available online at https://aspe.hhs.gov/basic-report/evolving-roles-public-and-private-agencies-privatized-child-welfare-systems

18. U.S. Department of Health and Human Services. NSCAW State Child Welfare Agency Survey: Report. 2001. Available online at https://www.acf.hhs.gov/opre/resource/nscaw-state-child-welfare-agency-survey-report

19. Jones AC, LaLiberte T, Piescher KN. Defining and strengthening child well-being in child protection. Children and Youth Services Review. 2015; 54: 57-70.

20. Burns-Jager K, Bozek K, Horsford S. Calculating all of our losses: Writing real-world therapy experiences in child welfare. Journal of Feminist Family Therapy: An International Forum. 2012; 24: 79-100. doi:https://doi.org/10.1080/08952833.2012.631862

21. Shea SS. Finding parallels: The experiences of clinical social workers providing attachment-based treatment to children in foster care. Clinical Social Work Journal. 2015; 43: 62-76.

22. Kerns SE, Pullmann MD, Putnam B, et al. Child welfare and mental health: Facilitators of and barriers to connecting children and youths in out-of-home care with effective mental health treatment. Children and Youth Services Review. 2014; 46: 315-324. doi: https:// doi.org/10.1016/j.childyouth.2014.09.013

23. Marcenko MO, Hook JL, Romich JL, et al. Multiple jeopardy: Poor, economically disconnected, and child welfare involved. Child Maltreatment. 2012; 17: 195-206. doi: https://doi.org/10.1177/1077559512456737

24. Arbeiter E, Toros K. Parental engagement in child protection assessment: A qualitative analysis of worker and parent perspectives. International Social Work. 2017; 60: 1469-1481.

25. Darlington Y, Healy K, Feeney JA. Challenges in implementing participatory practice in child protection: A contingency approach. Children and Youth Services Review. 2010; 32: 1020-1027.

26. Hulbert MS, Leslie LK, Landsverk J, et al. Contextual predictors of mental health service use among children open to child welfare. Archives of General Psychiatry. 2004; 61: 1217-1224.

27. Raghavan R, Inoue M, Ettner SL, et al. A preliminary analysis of the receipt of mental health services consistent with national standards among children in the child welfare system. American Journal of Public Health. 2010; 100: 742-749.

28. Glisson C, Green P. The effects of organizational culture and climate on the access to mental health care in child welfare and juvenile justice systems. Administration and Policy in Mental Health and Mental Health Services Research. 2006; 33: 433-448. doi: https:// doi.org/10.1007/s10488-005-0016-0

29. Strolin-Goltzman J, Kollar S, Trinkle J. Listening to the voices of children in foster care: Youths speak out about child welfare workforce turnover and selection. Social Work. 2010; 55: 47-53. doi: https://doi.org/10.1093/sw/55.1.47

30. Claiborne N, Auerbach C, Zeitlin W, et al. Climate factors related to intention to leave in administrators and clinical professionals. Children and Youth Services Review. 2015; 51: 18-25. doi:https://doi.org/10.1016/j.childyouth.2015.01.007 
31. Barth RP, Landsverk J, Chamberlain P, et al. Parent-training programs in child welfare services: Planning for a more evidence based approach to serving biological parents. Research on Social Work Practice. 2005; 15: 353-371.

32. Barth RP. The move to evidence-based practice: How well does it fit child welfare services? Journal of Public Child Welfare. 2008; 2: $145-171$.

33. Akin BA, Mariscal SE, Bass L, et al. Implementation of an evidence-based intervention to reduce long-term foster care: Practitioner perceptions of key challenges and supports. Children and Youth Services Review. 2014; 46: 285-293.

34. Horwitz SM, Chamberlain, P, Landsverk J, et al. Improving the mental health of children in child welfare through the implementation of evidence-based parenting interventions. Administration and Policy in Mental Health. 2010; 37: 27-39.

35. Staudt M, Massengale K. Parents involved with child welfare: Their perceptions of mental health services. Social Work in Mental Health. 2015; 13: 336-348. doi:https://doi.org/10.1080/15332985.2014.936544

36. Garcia AR, Circo E, DeNard C, et al. Barriers and facilitators to delivering effective mental health practice strategies for youth and families served by the child welfare system. Children and Youth Services Review. 2015; 52: 110-122.

37. Adoption and Safe Families Act of 1997. P. L. 105-89. (1997).

38. Marshall C, Rossman GB. Designing qualitative research, $5^{\text {th }}$ Edition. Thousand Oak, CA: Sage Publications, Inc; 2010.

39. Palinkas LA, He AA, Choy-Brown M, et al. Operationalizing social work science through research-practice partnerships: Lessons from implementation science. Research on Social Work Practice. 2017; 27: 181-188.

40. Scientific Software Development (Germany). Scientific Software Development's ATLAS.ti. Berlin, Germany: Scientific Software Development; 2002.

41. Braun V, Clarke V. Using thematic analysis in psychology. Qualitative Research in Psychology. 2006; 3: 77-101.

42. Boyatzis R. Transforming qualitative information: Thematic analysis and code development. Thousand Oaks, CA: Sage; 1998

43. Findlay L, Gough B. Reflexivity: A practical Guide for Researchers in Health and Social Sciences. Oxford: Blackwell Publishing; 2003.

44. Author. 2017

45. Chandler SM. Managing innovative collaborations: The role of facilitation and other strategies for working collaboratively. Human Service Organizations: Management, Leadership \& Governance. 2017; 41: 133-146. doi: https://doi.org/10.1080/ 23303131.2016.1229708

46. Silverman E. Moving beyond collaboration: A model of enhancing social work's organizational empathy. Social Work. 2018; 63: 297304. doi: https://doi.org/10.1093/sw/swy034

47. Cahalane H, Sites EW. The climate of child welfare employee retention. Child Welfare: Journal of Policy, Practice, and Program. 2008; 87: 91-114.

48. Ellett AJ, Ellis JI, Westbrook TM, et al. A qualitative study of 369 child welfare professionals' perspectives about factors contributing to employee retention and turnover. Children and Youth Services Review. 2007; 29: 264-281, https:/doi.org/10.1016/ j.childyouth.2006.07.005.

49. Williams SE, Nichols Q, Kirk A, et al. A recent look at the factors influencing workforce retention in public child welfare. Children and Youth Services Review. 2011; 33: 157-160, https://doi.org/10.1016/j.childyouth.2010.08.028.

50. Jones L, Packard T, Nahrstedt K. Evaluation of a training curriculum for inter-agency collaboration. Journal of Community Practice. 2002; 10: 23-40.

51. Whiteley RF, Gillespie J, Robinson C, et al. Effective teaching and learning in interprofessional education in child welfare. Journal of Education and Training Studies. 2014; 2: 148-158.

52. Strand VC, Badger L. Professionalizing child welfare: An evaluation of clinical consultation model for supervisors. Children and Youth Services Review. 2005; 27: 865-880. doi:https://doi.org/10.1016/j.childyouth.2004.12.001

53. Chuang E, Wells R. The role of inter-agency collaboration in facilitating receipt of behavioral health services for youth involved with child welfare and juvenile justice. Children and Youth Services Review. 2010; 32: 1814-1822. doi:https://doi.org/10.1016/ j.childyouth.2010.08.002

54. Blakey JM, Leathers SJ, Lawler M, et al. A review of how states are addressing placement stability. Children and Youth Services Review. 2012; 34: 369-378. doi:https://doi.org/10.1016/j.childyouth.2011.11.007

55. Christiansen O, Havik T, Anderssen N. Arranging stability for children in long-term out-of-home care. Children and Youth Services Review. 2010; 32: 913-921 doi:https://doi.org/10.1016/j.childyouth.2010.03.002

56. Dagan SW, Ben-Porat A, Itzhaky H. Child protection workers dealing with child abuse: The contribution of personal, social and organizational resources to secondary traumatization. Child Abuse \& Neglect. 2016; 51: 203-211. doi:https:/doi.org/10.1016/ j.chiabu.2015.10.008.

57. Sprang G, Craig C, Clark J. Secondary traumatic stress and burnout in child welfare workers: A comparative analysis of occupational distress across professional groups. Child Welfare. 2011; 90: 149-168.

58. Kim A, Mor Barak ME. The mediating roles of leader-member exchange and perceived organizational support in the role stressturnover intention relationship among child welfare workers: A longitudinal analysis. Children and Youth Services Review. 2015; 52: 135-143. doi: https://doi.org/10.1016/j.childyouth.2014.11.009

59. McCrae JS, Scannapieco M, Obermann A. Retention and job satisfaction of child welfare supervisors. Children and Youth Services Review. 2015; 59: 171-176. doi:https://doi.org/10.1016/j.childyouth.2015.11.011

60. Estefan LF, Coulter ML, VandeWeerd CL, et al. Receiving mandated therapeutic services: Experiences of parents involved in the child welfare system. Children and Youth Services Review. 2012; 34: 2353-2360. doi: https://doi.org/10.1016/j.childyouth.2012.09.002

Publisher's Note Springer Nature remains neutral with regard to jurisdictional claims in published maps and institutional affiliations. 